\title{
Assessment Scale of Physical Activity Report Card Applications
}

\author{
Fatih Özgül ${ }^{1}$, Murat Kangalgil ${ }^{1}$, Oğuzhan Çal1 ${ }^{1}$, Rahmi Yıldız ${ }^{1}$
}

${ }^{1}$ Cumhuriyet University, fozgul@cumhuriyet.edu.tr

Received: 03.11.2017

Accepted: 19.12.2017

Online Published: 08.03.2018

doi: 10.30655/besad.2018.1

\begin{abstract}
The purpose of the research in this context is to develop the Physical Activity Carrying Practice Scale, which can help determine how well these practices are being done to physical education teachers who are involved in physical activity training.The draft scale, composed of 46 items and prepared by the researchers, was applied to 414 physical education and sports teachers of whom 298 male and 116 female. The obtained data set was analyzed by factor analysis and varimax rotation technique and it was seen that 38 items with load values above 0,40 were collected in six factors named "Applicability, Impact, Difficulties, Enforcement, Competence and Support".Thescaleexplains 61,555\% of the total variance with thi sstructure. As a result of the Confirmatory Factor Analysis, the fit indices of the sub-factor model were obtained at an acceptable level, and the inter-dimensional correlations were determined at the expected level. For the total of the scale, 0,83 and for the sub-dimensions, respectively; 0.87 for the Applicability sub-dimension, 0.80 for the Impact sub-dimension, 0.57 for the Difficult sub-dimension, 0.82 for the Sufficiency sub-dimension, and 0.76 for the Support sub-dimension and 0.76 Cronbach Alpha ( $\alpha$ ) internal consistency coefficients were calculated. There are 3 reverse scoring items on the scale and the total score from the scale ranges from 38 to 190. The internal consistency coefficients obtained for the whole scale and sub-dimensions of the Physical Activity Carrying Practice Scale developed in the study were found to be at a good level. The total variance explained by the factor loads is above the expected level. As a result, a validand reliable scale suitable for physical education and sport teachers participating in physical activity measurement was obtained.
\end{abstract}

Keywords: Physical Education Teacher, Physical Activity Reports, Practice, Scale

\section{Fiziksel Etkinlik Karnesi Uygulamaları Değerlendirme Ölçeğinin Geliştirilmesi}

Öz

Bu araştırmanın amacı fiziksel etkinlik karnesi eğitimine katılan beden eğitimi öğretmenlerinin, bu ölçüm uygulamalarını ne denli başarılı bir şekilde yapıldığını belirlemeye yardımcı olabilecek Fiziksel Etkinlik Karnesi Uygulamaları Ölçeğinin geliştirilmesidir. Araştırmacılar tarafindan hazırlanan ve 46 maddeden oluşan taslak ölçek 298 erkek ve 116 kadın olmak üzere 414 beden eğitimi ve spor öğretmenine uygulanmıştır. Elde edilen veri seti, faktör analizi, varimax döndürme tekniği ile incelenerek, 0,40'un üstünde yük değeri alan 38 maddenin "Uygulanabilirlik, Etki, Güçlükler, Zorlayıcllı, Yeterlilik ve Destek" isimleri verilen altı faktörde toplandiğı görülmüştür. Ölçek bu yapısıyla toplam varyansın \%61,555'ini açıklamıştır. Doğrulayıcı Faktör Analizi sonucuna göre alt faktörlü modelin uyum indeksleri güçlü olarak kabul edilebilir düzeyde elde edilirken, boyutlar arası bağıntılar beklenen düzeyde belirlenmiştir. Ölçeğin Cronbach Alpha ( $\alpha$ ) iç tutarlılık katsayıları bütünü için 0,83 ve alt boyutlar için ise sirasıyla; Uygulanabilirlik alt boyutu için 0,87, Etki alt boyutu için 0,80, Güçlükler alt boyutu için 0,57, Zorlayıcılık alt boyutu için 0,75, Yeterlilik alt boyutu için 0,82 ve Destek alt boyutu için de 0,76 olarak hesaplanmıştır. Ölçekte 3 tane ters puanlanan madde bulunmaktadır ve ölçekten alınabilecek toplam puan 38 ile 190 arasında değişmektedir. Araştırma sonucunda geliştirilen Fiziksel Etkinlik Karnesi Uygulama Ölçeğinin bütünü ve alt boyutları için elde edilen iç tutarlılık katsayılarının iyi düzeyde olduğu görülmüşı̈̈r. Faktör yükleri ile açılanan toplam varyansta beklenen seviyenin üzerinde bulunmuştur. Sonuç olarakfiziksel etkinlik karnesi ölçümlerine katılan beden eğitimi ve spor ögretmenleri için uygun geçerli ve güvenilir bir ölçek elde edilmiştir. 


\section{Giriş}

İnsan, canlı bir fiziksel varlık olarak yaşamını daha kaliteli bir şekilde devam ettirebilmesi için harekete ihtiyaç duymaktadır ve insan organizmasının hareket için yaratıldığ 1 belirtilmektedir (MEB, 2017). Teknolojik gelişmelerle günlük aktivite yoğunluğunu azaltmak her ne kadar yaşamı kolaylaştırsa da uzun vadede hareketsiz bireylerin sayısını arttırmakta ve sağlığı olumsuz etkilemektedir. Hareketsiz yaşam, günlük alışverişini bile bilgisayar başında sanal marketlerden gerçekleştiren modern toplum için en önemli problemlerin başında yer almaktadır. Giderek daha az mesafeler boyunca yürüyen, ev dışı aktivitelere daha az katılmaya başlayan kitleler, gün içeresinde harcadığı enerji miktarını azaltırken, beslenme sıklığı ve miktarını değiştirmemektedir. Fiziksel aktivite yetersizliği vücut üzerindeki olumsuz etkilerinin yanı sıra, vücut ağırlığında artışa neden olmaktadır (Seabra ve diğ.,2013). Dünya genelinde gün geçtikçe yetersiz fiziksel aktiviteye bağlı olarak artış gösteren aşırı vücut ağırlığı ve obezite, kalp-damar rahatsızlıkları, mental rahatsızlıklar, kas-iskelet yaralanmaları gibi sağlık sorunlarının habercisi niteliğinde olmaktadır (THSK, 2014). Fiziksel aktivite; kişinin enerji harcamasını artırdığı için modern toplumların karşı karşıya kaldığı en önemli sağlık problemlerinden birisi olan obezitenin önlenmesinde, enerji dengesinin ve vücut ağırlığının kontrolünü sağlamaktadır (THSK, 2017). Fiziksel hareketsizlik yalnızca yetişkinler için değil, çocuklar ve gençler için de ciddi bir sağlık riski taşımaktadır. Kronik hastalıkların oluşmasında genetik, çevresel ve biyolojik faktörlerin dışında en önemli etken, hareketsizlik ve hatalı beslenmedir. İleri yaşlarda görmeye alıştığımız birçok kronik hastalığın, hareketsiz yaşam tarzının benimsenmesinden dolayı, günümüzde artık çocukluk döneminde de ortaya çıktığı gözlenmektedir. Bu nedenle, bebeklik çağından itibaren çocuklarda hareketin artırılmasının ve gün içerisinde hareketsiz olarak geçirilen sürenin azaltılmasının ayrı bir önemi vardır. Çocukluk dönemi hastalıklarının yanı sıra, temelleri çocuklukta atılan pek çok hastalığın önlenmesi için özellikle okul çocuklarında düzenli fiziksel aktivite ve spor temel stratejilerin arasında yer almaktadır. Düzenli olarak yapılan fiziksel aktivitelerin, çocuklarda bilişsel gelişime katkı sağlayarak onların okul başarısını olumlu şekilde etkilediği ve daha sosyal ve düzenli bir yaşam alışkanlığı kazanmalarını sağladığı bilinmektedir (THSK, 2017). Çocuklarımızda, fiziksel aktivite alışkanlığının yerleşmesini sağlamak, sağlıklı bir yaşam tarzı geliştirmelerine yardımcı olmak, bu bağlamda fiziksel aktivite ile ilgili temel bilgi, beceri ve tutum geliştirmelerine katkı sağlamak için, okullarımıza özelliklede beden eğitimi ve spor öğretmenlerine büyük sorumluluk düşmektedir. Bu amaçla, Millî Eğitim Bakanlığı ve Sağlık Bakanlığı iş birliğinde sağlık için fiziksel aktivite projesi başlatılmıştır. Bu projeye bağlı olarak fiziksel aktivite uygunluk karne uygulamasının Türkiye genelinde (resmi-özel) ortaokul ve liselerde eğitim ve öğretim yılının birinci ve ikinci dönemlerinde olmak üzere yılda 2 kez 
düzenlenmesi ve uygulamada öğrencilerin mekik, şınav, otur-uzan esneklik ölçümü, vücut ağırlığg ve boy uzunluğu ölçümü yapılarak değerlendirilmesi kararlaştırılmıştır. Bu bağlamda, beden eğitimi ve spor öğretmenleri zümre başkanlarına Milli Eğitim Bakanlığı işbirliğinde hazırlanan eğitim videolarının tanıtılacağı “eğitici eğitimleri” yapılmış, sağlık için hareket ve fiziksel aktivitenin öneminin de anlatıldığı bu sunumlar, Sağlık Bakanlığı bilim kurulu eğitmenlerinin katılımı ile uygulamaya geçirilmiştir. Ülkemizde yeni olan fiziksel aktivite uygunluk karne uygulaması ile ilgili çalışmalar, gerek Milli Eğitim Bakanlığı gerekse Sağlık Bakanlığı bünyesinde fiziksel aktivitenin önemine dikkat çekilmesi ve bu konu hakkında mevcut durumun tespit edilebilmesi açısından önem arz etmektedir. Buradan hareketle, bu araştırmanın amacı; çocuklarımıza sağlıklı, üretken, kaliteli bir gelecek sağlayabilmek açısından fiziksel etkinlik karnesi uygulamalarının beden eğitimi öğretmenleri tarafindan ne denli başarılı bir şekilde yapıldığını belirlemeye yardımcı olabilecek "Fiziksel Etkinlik Karnesi Uygulamaları Ölçeğinin” geliştirilmesidir.

\section{Yöntem}

\section{Araştırma Grubu}

Araştırma kapsamında verilerin toplanabilmesi için hazırlanan ölçme aracı taslağı, araştırmaya katılmayı kabul eden ve fiziksel etkinlik karne uygulamaları eğitimini almış, olan, 298 erkek ve 116 kadın olmak üzere toplam 414 beden eğitimi ve spor öğretmenine uygulanmıştır.

\section{Ölçeğin Geliştirilmesi}

Ölçek geliştirmenin ilk aşamasında literatür incelenerek, beden eğitimi ve spor öğretmenlerinin sahip olması gereken yeterlilikler belirlenmeye çalışılmıştır. Bu kapsamda yurt içi ve yurtdışı bu alanda yapılan çalışmalar ile MEB tarafından planlanan Fiziksel Etkinlik Karne Uygulamaları Eğitimleri yeterlilikler açısından değerlendirilmiş ve ölçekte yer alabilecek ifadeler belirlenmiştir. Böylece 46 maddelik bir madde havuzu oluşturulmuştur. Maddelerin oransal olarak birbirlerine yakınlığından ziyade, tasarlanan alt boyutların kapsamlarına dahil olma özellikleri göz önünde bulundurulmuştur. Oluşturulan 46 maddelik taslak form, uzman görüşleri alınmak üzere alanda bilgi sahibi olan ve araştırma konusu hakkında bilgilendirilen Spor Bilimleri ve Eğitim Bilimleri alanından 10 uzmanın görüşüne sunulmuştur. Uzmanlardan gelen dönütler yardımıyla ölçeğin son hali verilmeye çalışılmıştır. Bu süreçte; uzman görüşleri doğrultusunda maddelerin kapsam geçerliği Veneziano ve Hooper (1997; akt. Yurdagül, 2005) tarafından geliştirilen kapsam geçerlik oranı ile belirlenmiştir. Söz konusu oranlar her madde için olumlu yanıt veren uzman sayısı toplamının toplam uzman sayısına oranının bir eksiği alınarak belirlenmiştir. $\mathrm{Bu}$ işlemlerin ardından 46 maddelik deneme formu oluşturulurken araştırmaya 
katılacak olanlardan "Kesinlikle katılıyorum" ile "Kesinlikle katılmıyorum" arasında değişen likert tipi 5'li bir ölçek üzerinde kendi algılarını ifade etmeleri beklenmiştir.

\section{Verilerin Toplanması}

Araştırmacılar tarafından hazırlanan ve 46 maddeden oluşan taslak ölçek araştırmaya katılmayı kabul eden ve Fiziksel Etkinlik Karnesi Uygulamaları Eğitimini almış olan 298 erkek ve 116 kadın olmak üzere toplam 414 beden eğitimi ve spor öğretmenine 2016- 2017 öğretim yılı bahar döneminin sonunda uygulanmıştır.

\section{Verilerin Analizi}

Araştırmaya katılmayı kabul eden 414 beden eğitimi ve spor öğretmeninden gelen yanıtlar 1şığında ölçeğin geçerlik ve güvenirlik çalışmaları yapılmıştır. Araştırmada kullanılan örneklem büyüklügü incelenmiş ve faktör analizinin yapılabilmesi için yeterli görülmüştür (Tabachnick ve Fidell, 2001). “Fizikse Etkinlik Karnesi Uygulamaları Değerlendirme Ölçeği” nin yapı geçerliğini belirlemek için Varimax döndürme ile temel bileşenler analizi kullanılarak Açıklayıcı Faktör Analizi (AFA) yapılmıştır. Analizde faktör yükleri en az .40 olarak belirlenmiştir (Büyüköztürk ve diğ.,2012). Faktör Analizine başlamadan önce verilerin uygunluğunu saptamak için, Kaiser-Meyer-Olkin (KMO) katsayısı ve Barlett's sphericity testi kullanılarak hesaplanmıştır. KMO değeri .84 bulunmuş ve Barlett's testi sonucu da $\left(\div^{2}=9889.34, \mathrm{p}=0,000\right)$ anlamlı çıkmıştır (George ve Mallery, 2001). Elde edilen veri seti, faktör analizi, Varimax döndürme tekniği ile incelenerek, 0,40'un üstünde yük değeri alan 38 maddenin altı faktörde toplandığı görülmüş ve bu faktörler "Uygulanabilirlik, Etki, Güçlükler, Zorlayıcılık, Yeterlilik ve Destek” alt başlıkları ile isimlendirilmiştir. Ölçek bu yapısıyla toplam varyansın \%61,555’ini açıklamıştır. Doğrulayıcı Faktör Analizi sonucuna göre alt faktörlü modelin uyum indeksleri güçlü olarak kabul edilebilir düzeyde elde edilirken, boyutlar arası bağıntılar beklenen düzeyde belirlenmiştir. Ölçeğin bütünü için 0,83 ve alt boyutlar için ise sırasıyla; Uygulanabilirlik alt boyutu için 0,87, Etki alt boyutu için 0,80, Güçlükler alt boyutu için 0,60, Zorlayıcılık alt boyutu için 0,75, Yeterlilik alt boyutu için 0,82 ve Destek alt boyutu için de 0,76 Cronbach Alpha $(\alpha)$ iç tutarlılık katsayıları hesaplanmıştır. Ölçekte 3 tane ters puanlanan madde bulunmaktadır ve ölçekten alınabilecek toplam puan 38 ile 190 arasında değişmektedir.

\section{Bulgular}

Bu bölümde ölçeğin geliştirilmesi için toplanan verilere ait değerlendirmeler tablolar halinde verilmiştir. 
Tablo 1. Faktör Yük Değerleri Tablosu

\begin{tabular}{|c|c|c|c|c|c|c|}
\hline \multicolumn{7}{|c|}{ Faktör Yük Değerleri } \\
\hline Madde & $\begin{array}{c}\text { Faktör } 1 \\
\text { AFA* }\end{array}$ & $\begin{array}{c}\text { Faktör } 2 \\
\text { AFA* }\end{array}$ & $\begin{array}{c}\text { Faktör } 3 \\
\text { AFA* }\end{array}$ & $\begin{array}{c}\text { Faktör } 4 \\
\text { AFA* }\end{array}$ & $\begin{array}{c}\text { Faktör } 5 \\
\text { AFA* }\end{array}$ & $\begin{array}{c}\text { Faktör } 6 \\
\text { AFA* }\end{array}$ \\
\hline M46 & ,746 & & & & & \\
\hline M40 & ,732 & & & & & \\
\hline M41 & ,683 & & & & & \\
\hline M37 & 659 & & & & & \\
\hline M42 & ,578 & & & & & \\
\hline M9 & ,577 & & & & & \\
\hline M13 &, 571 & & & & & \\
\hline M35 & ,536 & & & & & \\
\hline M45 & ,525 & & & & & \\
\hline M43 &, 515 & & & & & \\
\hline M12 & ,487 & & & & & \\
\hline M39 & ,446 & & & & & \\
\hline M28 & & ,861 & & & & \\
\hline M32 & & ,779 & & & & \\
\hline M29 & & ,739 & & & & \\
\hline M33 & & ,737 & & & & \\
\hline M30 & & ,725 & & & & \\
\hline M36 & & ,715 & & & & \\
\hline M27 & & ,711 & & & & \\
\hline M31 & & ,602 & & & & \\
\hline M34 & &,- 552 & & & & \\
\hline M19 & & & ,795 & & & \\
\hline M21 & & & ,689 & & & \\
\hline M22 & & & 670 & & & \\
\hline M16 & & & ,662 & & & \\
\hline M18 & & &,- 618 & & & \\
\hline M17 & & & ,585 & & & \\
\hline M14 & & & & 818 & & \\
\hline M44 & & & & 697 & & \\
\hline M15 & & & & 666 & & \\
\hline M4 & & & & & ,774 & \\
\hline M5 & & & & & ,765 & \\
\hline M6 & & & & & 612 & \\
\hline M8 & & & & & 578 & \\
\hline M25 & & & & & &,- 787 \\
\hline M20 & & & & & &,- 682 \\
\hline M23 & & & & & &,- 671 \\
\hline M24 & & & & & &, 551 \\
\hline
\end{tabular}

* (AFA) Açıklayıcı faktör analizine ait faktör yükleri

Tablo 1'de açıklayıcı ve doğrulayıcı faktör analizine ait faktör yükleri verilmiştir. Tabloya göre birinci boyut 12 maddeden, ikinci boyut 9 maddeden, üçüncü boyut 6 maddeden, dördüncü boyut 3 maddeden, beşinci boyut 4 maddeden ve altıncı boyut 4 maddeden olmak üzere toplam ölçek 38 maddeden oluşmaktadır. 
Tablo 2. Açıklanan Toplam Varyans Tablosu

\begin{tabular}{cccc}
\hline \multirow{2}{*}{ Component } & Total & $\begin{array}{c}\text { Extraction Sums of Squared Loadings } \\
\text { \% of Variance }\end{array}$ & Cumulative \% \\
\hline 1 & 8,515 & 22,407 & 22,407 \\
2 & 5,039 & 13,261 & 35,669 \\
3 & 4,052 & 10,664 & 46,333 \\
4 & 2,775 & 7,302 & 53,635 \\
5 & 1,694 & 4,458 & 58,092 \\
6 & 1,316 & 3,462 & 61,555 \\
\hline
\end{tabular}

Tablo 2’de tüm faktörlerin toplam varyansın 61.555'ini açıkladığı görülmüştür.

Tablo 3. Faktörler Arası Korelasyon Katsayıları Tablosu

\begin{tabular}{|c|c|c|c|c|c|c|}
\hline \multicolumn{7}{|c|}{ Faktörler Arası Korelasyon Katsayıları } \\
\hline & Uygulanabilirlik & Etki & Güçlükler & Zorlayıcılık & Yeterlilik & Destek \\
\hline Uygulanabilirlik & 1 & ,380** &,$- 175^{* *}$ &, $207^{* *}$ &, $594^{* *}$ &,$- 191^{* *}$ \\
\hline Etki & & 1 &,$- 125^{*}$ &, $285^{* *}$ &, $182^{* *}$ & ,033 \\
\hline Güçlükler & & & 1 &,$- 111^{*}$ & $105^{*}$ & $145^{* *}$ \\
\hline Zorlayıcılık & & & & 1 &, $121^{*}$ &, $115^{*}$ \\
\hline Yeterlilik & & & & & 1 &,$- 186^{* *}$ \\
\hline Destek & & & & & & 1 \\
\hline
\end{tabular}

Tablo 3'e göre faktörler arası korelasyon katsayıları incelendiğinde Açıklayıcı Faktör Analizinde (AFA) ortaya konulan yapının doğrulandığ1 görülmüştür. Bu sonuç aynı zamanda oluşturulan boyutların istatistiki olarak doğrulandığını da göstermektedir.

Şekil 1.

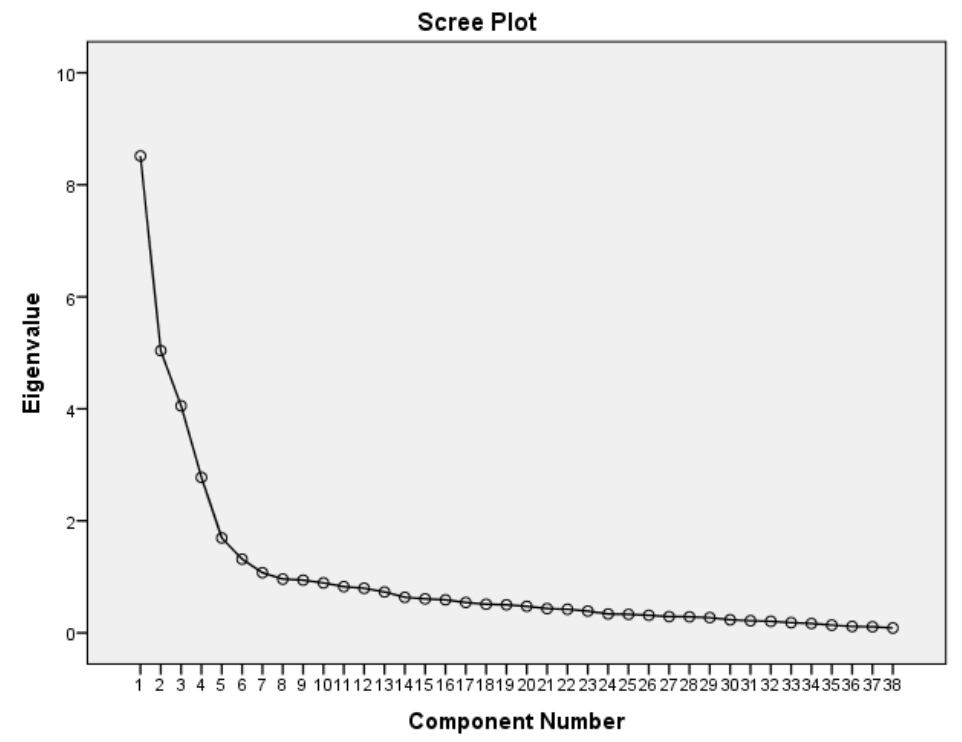




\section{Sonuç}

Alanyazın incelendiğinde, fiziksel etkinlik karnesi uygulamaları ile ilgili ulusal bir çalışmaya rastlanılmamıştır. Ancak fiziksel etkinlik karne uygulamaları uluslararası alanda oldukça yaygındır. Birçok ülkede gerçekleştirilen araştırmalarda fiziksel etkinliğe öğrencilerin katılımları rapor edilmektedir (Pateve diğ., 2006; Sarmiento ve diğ., 2010; Brockman, Jago, Fox 2011; Colley, Brownrigg, Tremblay, 2012; Herman ve diğ., 2014; Burrows ve di ̌̆., 2014; Moreno ve diğ., 2015; Anderson ve diğ., 2016; WHO, 2016). Ülkemizde fiziksel etkinliğe katılım düzeylerini öğretmenler açısından değerlendirebilen bir ölçek bulunmamaktadır. Bu bağlamda araştırmada geliştirilen ölçeğin uygulamada beden eğitimi ve spor öğretmenlerinin fiziksel etkinlik karnesi uygulamalarını değerlendirmelerine katkılar sağlayacağı düşünülmektedir.

Araştırma sonucunda geliştirilen Fiziksel Etkinlik Karnesi Uygulama Ölçeğinin bütünü ve alt boyutları için elde edilen iç tutarlılık katsayılarının iyi düzeyde olduğu, faktör yükleri ile açıklanan varyansın da toplam varyansta beklenen seviyenin üzerinde bulunduğu görülmüştür. Sonuç olarak, beden eğitimi ve spor öğretmenlerinin fiziksel etkinlik karnesi ölçümleri ile ilgili sorunları değerlendirebilecekleri uygun, geçerli ve güvenilir bir ölçek elde edilmiştir.

\section{Öneriler}

$\mathrm{Bu}$ araştırmada geliştirilen ölçek Fiziksel Etkinlik Karnesi Uygulamalarının ülkemizde yaygınlaşması ile birlikte daha büyük bir örneklem grubuna uygulanabilir.

Geliştirilen ölçek diğer ülkelerdeki örnekleriyle karşılaştırılabilir.

\section{Kaynakça}

Anderson Steeves, E. T., Johnson, K. A., Pollard, S.L., Jones, S.J., Pollack, K., Lindstrom, J.S., Hopkins, L., Gittelshon, J. (2016). Social Influence Son Eating and Physical Activity Behaviours of Urban, Minority Youths. Public Health Nutr; 1-11.

Brockman, R., Jago, R., Fox, K. R. (2011). Children’sactiveplay: Self-Reported Motivators, Barriers and Facilitators. BMC Public Health; 11:461.

Burrows, R., Correa-Burrows, P., Orellana, Y., Almagia, A., Lizana, P., Ivanovic, D. (2014). Scheduled Physical Activity is Associated with Better Academic Performance in Chilean School-Age Children. J. Phys Act Health; 11(8):1600-1606. Pub Med doi:10.1123/jpah.2013-0125.

Büyüköztürk, Ş., Kılıç Çakmak, E., Akgün, Ö.E., Karadeniz, Ş. ve Demirel, F. (2012). Bilimsel Araştırma Yöntemleri. Ankara: Pegem Yayınları. 
Colley, R. C., Brownrigg, M., Tremblay, M. S. (2012) A Model of Knowledge Translation in Health: The Active Healthy Kids Canada Report Cardon Physical Activity for Children and Youth. Health Promot Pract.; 13(3):320-330.

Nicolas, A.F., Andrea, C.O’R., Kabir P., Sadarangani, A.V.O., Jaime, L., Macarena, V., Teresa B.C., Carolina, C., Nicolas, L., Magdalena, W., Carlos, C.M. (2016). Results From Chile’s 2016 Report Card on Physical Activity for Children and Youth. Journal of Physical Activity and Health; 13 (2), 117-123.

George, D., Mallery, P. (2001). SPSS for Windows Step By Step: A Simple Guide and Reference. Needham Heights: Allyn \& Bacon.

Herman, K. M., Paradis., G, Mathieu, M. E., O’Loughlin, J., Tremblay, A., Lambert, M. (2014). Association Between Accelerometer-Measured Physical Activity Intensities and Sedentary Time in 8- to 10-Year-Old Children. Pediatr Exerc Sci; 26 (1): 76-85.

MEB. (2017). Okul Sağlığı: - http://okulsagligi.meb.gov.tr/www/beden-egitimi-ve-spor-dersiogretmenlerine-verilecek-quotfiziksel-aktivite-uygunluk-karnesiquot-egitimi/icerik/47 adresinden 15.10.2017 tarihinde alınmıştır.

Moreno, L., Cano, M., Orellana, Y., Kain, J. (2015). Compliance of Physical Activity Guidelines by Chilean Low-Income Children: Difference Between School and Weekend Days and Nutritional Status. Nutr Hosp; 31(5): 2195-2201.

Pate, R.R., Davis, M.G., Robinson, T.N., Stone, E.J., McKenzie, T.L., Young, J.C. (2006). Promoting Physical Activity in Children and Youth: A Leadership Role for Schools: A Scientific Statement from the American Heart Association Council on Nutrition, Physical Activity, and Metabolism (Physical Activity Committee) in collaboration with the Councils on Cardiovascular Disease in the Young and Cardiovascular Nursing. Circulation;114(11):1214-1224.

Sarmiento, O., Torres, A., Jacoby, E., Pratt, M., Schmid, T. L., Stierling, G. (2010). The CicloviaRecreativa: A Mass-Recreational Program with Public Health Potential. J PhysAct Health; 7 (Suppl 2):Pp 163-180.

Seabra, A., Mendoça, D., Maia, J., Welk, G., Brustad, R., Fonseca, A., Seabra, A. (2013). Gender, Weight Status And Socioeconomic Differences in Psychosocial Correlates of Physical Activity in School Children. Journal of Scienceand Medicine in Sport, 320-326.

Tabachnick, B. G., Fidell, L. S. (2001). Using Multivariate Statistics (4th Ed). Needham Heights: Allyn \& Bacon 
THSK. (2014). Türkiye Halk Sağlığı Kurumu. Türkiye Fiziksel Aktivite Rehberi. Ankara: Sağlık Bakanlığı.

THSK. (2017). Türkiye Halk Să̆lı̆g Kurumu. http://ailehekimligi.gov.tr/salk-ve-bakm/265fiziksel-aktivite.html adresinden 10.10.2017 tarihinde alınmıştır.

University of Southern Denmark Research and Innovation Centrefor Human Movement and Learning (2016). The Danish Physical Activity Report Card for Children and Youth.

WHO (2016) World Health Organization. Global School-based Student Health Survey (GSHS). http://www.who.int/chp/gshs/en/. Accessed July 26, 2016.

Yurdagül, H. (2005). Ölçek Geliştirme Çalışmalarında Kapsam Geçerlik İndeksinin Kullanımı. 14. Eğitim Bilimleri Kongresi, Pamukkale Üniversitesi, Denizli.

Yüzgül, A., Müniroğlu, S. (2001). Ankara'da Özel Bir Okulda 7-12 Yaş Grubu Çocukların Fiziksel Özelliklerinin İncelenmesi. 3. Uluslararası Akdeniz Spor Bilimleri Kongresi, (s. 343-356). Antalya. 